\title{
Impact of a Multisport Recreation Program on Fitness Markers of Youth
}

\author{
Duston Morris ${ }^{1, *}$, Katie Helms ${ }^{2}$, Joan Brewer ${ }^{3}$ \\ ${ }^{1}$ Department of Health Sciences, University of Central Arkansas, 201 Donaghey Avenue, Conway Arkansas \\ ${ }^{2}$ Department of Health and Human Performance, University of Arkansas at Little Rock, DKSN 515, \\ 2810 South University Ave. Little Rock, AR \\ ${ }^{3}$ The Teachers College, Emporia State University, Visser Hall, 211, 1 Kellogg Circle, Emporia, KS \\ *Corresponding author: dustonm@uca.edu
}

Received December 07, 2018; Revised January 11, 2019; Accepted January 24, 2019

\begin{abstract}
Team sports are frequently used in activity and obesity intervention programs for youth, and are associated with increased physical activity levels and other positive changes in fitness markers. However, constraints and disparities associated with traditional, structured team sports warrant investigation of alternative sport types that may also be associated with positive physical changes among youth. Multisport activity that combines pursuits such as swimming, biking, and running breaks from traditional sports and may offer youth alternative activities that promote fitness. The current study sought to examine the effect of a 7-week multisport activity on physical fitness markers of youth. Results showed positive physical changes in weight, muscular endurance, and resting heart rate. Results may be used to identify multisport as an option for youth activity that is effective for physical change, but may not present some of the constraints associated with structured youth sport. Incorporating multisport activities into youth programming may enable skills that can be used to pursue related activities for a lifetime, when many are past the age of team sports participation.
\end{abstract}

Keywords: physical activity, youth fitness, multisport, team sports, health

Cite This Article: Duston Morris, Katie Helms, and Joan Brewer, "Impact of a Multisport Recreation Program on Fitness Markers of Youth.” Journal of Physical Activity Research, vol. 4, no. 1 (2019): 51-56. doi: 10.12691/jpar-4-1-6.

\section{Introduction}

The United States continues to experience an unprecedented rise in childhood obesity, and many children lack opportunities to participate in programs that help them shape healthy lifestyle characteristics. Furthermore, the obesity epidemic is more prevalent among minorities and lower socioeconomic communities. Nationally, disproportionate numbers of African-American children (22\%) and Hispanic children (23\%) are affected compared with white children (18\%) [1].

Previous studies demonstrate that exercise and recreation programs can produce higher levels of physical activity [2] and effective results for children with obesity [3]. However, many of these programs focus on traditional team sports or include activities that may not stimulate continued interest for children and adolescents [4]. Furthermore, many of the programs are difficult to reproduce due to special equipment or facilities, and children may be required to have a high level of skill in order to participate [4]. While structured team sport programs are frequently used as obesity interventions, the current study aims to investigate the efficacy of alternative activities, particularly lifestyle-oriented physical activity programs related to swimming, cycling, and running, to affect fitness-related health markers among youth.

Physical activity intervention programs have been shown to be successful in increasing physical health markers such as body weight, body mass index, and cardiovascular fitness levels [5,6]. Team sports are one activity type used successfully within the context of these programs $[7,8]$. Team sports are a popular youth activity in the United States, with over $56 \%$ of youth aged 6 to 12 having played a sport at least once a year [9]. In general, team sports are seen as a positive youth activity, with multiple social, physical, and developmental benefits $[10,11,12]$. Specific to health behaviors, youth sport participation is associated with important markers including increased physical activity levels and healthy body weight $[13,14]$.

However, while structured team sports may provide an effective activity model in obesity intervention programs, there are some constraints associated with the long-term efficacy of team sports to influence lifelong change, particularly among minority or economically disadvantaged populations. Such constraints may be responsible for declining participation rates, as well as high attrition rates as children age into adolescence and adulthood, which are concerns regarding such activities to be utilized throughout the lifespan. Participation in the largest team sports (football, basketball, baseball, and soccer) has been 
declining over the last 10 years [9]. In addition to general declining participation rates, sport participation decreases with age $[13,15]$. The increasing cost of participation may be one factor in this decline, illustrating one such barrier to the use of structured team sport programs as a lifestyle intervention $[16,17]$.

Participation in youth sports is much lower for children from low-income homes, with those from households earning less than $\$ 25,000$ per year being half as likely to play sports as children from households earning over $\$ 100,000$ per year [9]. Access and proximity to facilities is also a constraint to sport participation, particularly for youth in urban centers $[18,19]$. In addition to participation disparities among minority youth, the health benefits associated with organized sports participation are also similarly skewed. While health benefits of sports participation are well-documented, this relationship is stronger among white participants than black or Hispanic participants $[13,14]$.

While structural constraints such as cost and facility availability provide barriers to youth sport participation, a few intrapersonal constraints are worth addressing in considering sport as a lifestyle-oriented physical activity intervention. Pressure to win or achieve success measures imposed by parents or coaches is a frequently-reported reason for children choosing to stop sports participation. In addition, children may see sports as being overly structured, scheduled, and directed by adults, resulting in less ownership of their activities [17].

Considering issues in structured team sports that may not provide ideal outcomes for use in obesity intervention programs, fitness and lifestyle-oriented activities warrant attention as alternatives in such programs. Lifestyle-oriented sports are self-paced activities in which there are opportunities to participate throughout life, without the continued need for structured teams, leagues, personnel, or facilities. Multisport activities are a set or group of activities that are often combined into single activity efforts (such as duathlon or triathlon formats), but can also be performed as singular activities. Typically these activities include a combination of lifestyle-oriented sports such as swimming, biking, paddling, cycling, hiking, walking, and running.

Multisport activities that include running, cycling, and swimming continue to increase in popularity in the United States, while organized team sport participation is declining [20,21]. Multisport activities are associated with greater improvement of physical health indicators such as cardiovascular fitness and body composition than most team sports, and have lower injury rates [22,23]. Running and cycling also have higher continuation rates into adulthood than team sports, and participation in adolescence is predictive of further participation into adulthood [24,25]. Considering attrition in traditional team sports and uptake of activities such as running and jogging as youth age, it seems appropriate to investigate obesity interventions that utilize lifetime-oriented activities with better likelihood of participation into adulthood.

Multisport activities also have the potential to alleviate constraints associated with the high cost, specialized facilities, and need for teammates that structured team sports can present. Once children acquire the skills necessary to participate, multisport activities can be done very simply at the participants' discretion, in their own neighborhoods, and without teammates or coaches. The degree of competition or structure in multisport activities is determined by the participant. While structured opportunities for competition exist if participants prefer, multisport activities can also be performed on a casual, freely performed basis.

Lifestyle sports, particularly multisport activities including running, cycling, and swimming, may be good choices for obesity interventions in youth. Multisport activities are continued into adulthood, and have the potential to address many of the constraints associated with organized team sport activities, particularly for minority and economically disadvantaged youth. While physiological changes have been found to result from interventions using team sports [13], changes resulting from multisport warrant further study in investigating its potential as an additional intervention mode. Therefore, the purpose of this pilot study was to determine if participation in a seven-week summer multisport camp could enhance biological fitness markers among youth.

\section{Methods}

\subsection{Participants and Design}

The sample for this specific study consisted of 64 youth enrolled in a 7-week summer multisport camp. Participants were between 7 and 14 years of age. The researchers utilized a single-group pretest-posttest quasi-experimental design. Prior to the start of any fitness training using the multisport games and activities, all of the camp participants completed a battery of Fitness Tests using the FITNESSGRAM assessment. The FITNESSGRAM assessment includes assessment tests that measure aerobic capacity (i.e., The One-Mile Run/Walk; PACER), body composition (i.e., skinfold measurements; Body Mass Index-BMI), muscular strength and endurance (i.e., cadence-based curl-up test and $90^{\circ}$ push-up test), and flexibility (i.e., back saver sit and reach test). Each test and its criterion referenced standard have been measured for their reliability and validity [26]. Participants completed all pre-test and post-test FITNESSGRAM measurements.

For this particular study, data under review included selected measurements from the FITNESSGRAM plus two additional measurements. These were: 1 ) body weight as measure by weight loss, 2) muscular strength as measured by the $90^{\circ}$ push-up, 3) core strength as measured by the cadence-based curl-up test, 4) one mile run speed time, and 5) resting heart rate. Because this was a pilot test designed to address the changes as a result of participating in multisport activities, paired t-test analyses were conducted to compare differences between pre-test and post-test data on the selected set of fitness markers.

\subsection{Intervention}

The intervention consisted of a 7-week multisport summer camp program was utilized for the current study. Over the course of a seven-week camp, athletes participated in various multisport games and activities focused on developing swimming, bicycling, and running skills. Each week, participants engaged in a combination 
of multisport activities, muscular strength and endurance activities, flexibility activities, nutrition lessons, and cross curricular activities. Prior to participation in each activity, activity leaders provided an introduction to the topic and activities to be completed during that specific activity period. During each activity period, the activity leaders described and demonstrated the activities to be used during that period. Camp participants then engaged in the prescribed activities throughout the duration of the activity period or until successful completion. Each day of the 7-week camp, camp participants had an opportunity to review activities in which they engaged on the previous day and participate in new activities. Activity leaders also provided a question and answer period at the end of each camp session to discuss new topics and skills learned during the games and activities.

\subsection{Statistical Analysis}

For this study, descriptive analyses were used to determine the demographic characteristics of the study participants (Table 1) and percentage of participants who demonstrated change in a selected set of fitness markers. These fitness markers included: 1) body weight, 2) muscular strength, 3) core strength, 4) one mile run speed time, and 5) resting heart rate. Paired t-test analyses were also conducted in order to compare differences between pre-test and post-test data on the same set of selected fitness markers.

\subsection{Outcome Measures}

Of the 64 youth participants, 48\% were males and 52\% were females, with a mean age of 11.43 (Table 1). Within the ethnic makeup of the sample, 55\% of participants were African American, 22\% were Caucasian, 16\% were Hispanic, and 7\% reported as other. All of the participants were from a Mid-West urban area.

Table 1. Demographic Characteristics of Participants $(N=64)$

\begin{tabular}{|l|c|c|c|}
\hline Variable & $\mathbf{~ N}$ & $\mathbf{\%}$ & Cum\% \\
\hline Gender & & & \\
Male & 31 & 48.4 & 48.4 \\
Female & 33 & 51.6 & 100.0 \\
\hline Age & & & \\
6-8 years & 28 & 43.8 & 43.8 \\
9-11 years & 22 & 34.4 & 78.2 \\
12-14 years & 14 & 21.8 & 100.0 \\
\hline Race/Ethnicity & & & \\
Black & 35 & 54.7 & 54.7 \\
White & 14 & 21.9 & 76.6 \\
Hispanic & 10 & 15.6 & 92.2 \\
Other & 5 & 7.8 & 100.0 \\
\hline
\end{tabular}

For body weight (i.e. weight loss), 92\% of the subjects had weight reductions over the course of the 7-week camp (Table 2). Total weight lost was 210.9 pounds with average weight loss of 6.4 pounds per participant. A paired samples t-test was conducted to evaluate the impact of participation in the multisport curriculum on body weight. Results of the t-test demonstrated that there was a statistically significant decrease in body weight from pretest $(\mathrm{M}=109, \mathrm{SD}=31)$ to posttest $(\mathrm{M}=103$, $\mathrm{SD}=31.4) \mathrm{t}(35)=-7.24, \mathrm{p}<.0001$.

Table 2. T-test Results Comparing Weight Loss

\begin{tabular}{cccccccc}
\hline \multicolumn{7}{c}{ Pre-Camp } & \multicolumn{7}{c}{ Post-Camp } & & \\
\hline & M & SD & M & SD & t & df & Sig (2-tailed) \\
Weight Change & 109 & 31 & 103 & 31.5 & -7.24 & 35 & .0001 \\
\hline
\end{tabular}

For muscular strength (i.e. $90^{\circ}$ push-up), $85 \%$ of the subjects had an increase in total completed push-ups from pretest to posttest. Total number of push-ups completed was 172 with an average increase of 6 push-ups per athlete. A paired samples t-test was conducted to evaluate the impact of participation in the multisport curriculum on change in number of push-ups (Table 3). Results of the t-test demonstrated that there was a statistically significant increase in the total number of push-ups from pretest $(\mathrm{M}=18, \mathrm{SD}=2.03)$ to posttest $(\mathrm{M}=27, \mathrm{SD}=2.53)$ $\mathrm{t}(34)=4.78, \mathrm{p}<.0001$.

Table 3. T-test Results Comparing Total Push-up Change

\begin{tabular}{cccccccc}
\hline \multicolumn{7}{c}{ Pre-Camp } & \multicolumn{7}{c}{ Post-Camp } \\
& M & SD & M & SD & t & df & Sig (2-tailed) \\
Push-up Change & 18 & 2.03 & 27 & 2.53 & 4.78 & 34 & .0001 \\
\hline
\end{tabular}

For core strength (i.e. cadence-based curl-up), 93\% of the subjects had an increase in the total completed curl-ups from pretest to posttest. Total number of curl-ups completed was 700 with an average increase of 25 curl-ups per athlete. A paired samples t-test was conducted to evaluate the impact of participation in the multisport curriculum on change in number of curl-ups (Table 4). Results of the t-test demonstrated that there was a statistically significant increase in the total number of curl-ups from pretest $(\mathrm{M}=30, \mathrm{SD}=3.42)$ to posttest $(\mathrm{M}=50, \mathrm{SD}=4.1) \mathrm{t}(32)=5.14, \mathrm{p}<.0001$.

Table 4. T-test Results Comparing Total Curl-up Change

\begin{tabular}{cccccccc}
\hline \multicolumn{1}{c}{ Pre-Camp } & \multicolumn{7}{c}{ Post-Camp } \\
\hline & M & SD & M & SD & t & df & Sig (2-tailed) \\
Curl-up Change & 30 & 3.42 & 50 & 4.1 & 5.14 & 35 & .0001 \\
\hline
\end{tabular}

For resting heart rate (RHR) change, 69\% of the subjects had a decrease in RHR from pretest to posttest. Average change in RHR was a decrease of 12.2 beats per minute. A paired samples t-test was conducted to evaluate the impact of participation in the multisport curriculum on change in RHR (Table 5). Results of the t-test demonstrated that there was a statistically significant decrease in RHR from pretest $(\mathrm{M}=80, \mathrm{SD}=2.0)$ to posttest $(\mathrm{M}=74, \mathrm{SD}=2.1) \mathrm{t}(28)=-2.1, \mathrm{p}<.02$.

Table 5. T-test Results Comparing Resting Heart Rate Change

\begin{tabular}{cccccccc}
\hline \multicolumn{7}{c}{ Pre-Camp } & \multicolumn{7}{c}{ Post-Camp } & & \\
& M & SD & M & SD & t & df & Sig (2-tailed) \\
RHR Change & 80 & 2.0 & 74 & 2.1 & -2.1 & 28 & .02 \\
\hline
\end{tabular}


There was no change in one mile run speed time among the participants. A paired samples t-test was conducted to evaluate the impact of participation in the multisport curriculum on change in one mile run speed. Results of the paired sample t-test (Table 6) demonstrated that there was no statistically significant difference in one mile run speed from pretest $(\mathrm{M}=12.2, \mathrm{SD}=.41)$ to posttest $(\mathrm{M}=12.2, \mathrm{SD}=.71) \mathrm{t}(21)=.02, \mathrm{p}<.49$. These results suggest that significant changes occurred in biological markers as the result of participating in the 7-week TriMasters multisport summer camp.

Table 6. T-test Results Comparing One Mile Run Speed

\begin{tabular}{cccccccc}
\hline \multicolumn{1}{c}{ Pre-Camp } & \multicolumn{1}{c}{ Post-Camp } \\
\hline & M & SD & M & SD & t & df & Sig (2-tailed) \\
Weight Loss & 12.2 & .41 & 12.2 & .71 & .02 & 21 & .49 \\
\hline
\end{tabular}

\section{Discussion}

This study intended to determine if participation in a 7-week youth multisport camp might impact biological markers among youth. The results of this current study demonstrated that participation in the 7-week multisport camp had a significant impact on body weight, muscular strength, core strength, and resting heart rate. More specifically, these findings illustrate that even short-term participation in multisport camps can significantly impact health-related outcomes for youth.

The primary objective of this research study was to address the impact of a 7-week multisport camp on fitness markers for youth. However, the quintessence of this research illustrates the potential for lifetime-oriented activities with high adult continuation rates to positively affect health. In particular, the current study shows that positive results related to physiological change can be obtained from such multisport activities, adding these activities to potential options for obesity and physical activity programs. It should be noted that a high number of participants were from minority groups who are underserved by traditional, organized sports [13,14]. Findings indicating positive physical change after participation in multisport activities in these specific groups show promise in identifying ways to address disparities in benefits seen from traditional team sports.

Establishing multisport activities as effective choices for physical health interventions in youth addresses several constraints related to organized sport programs, as well as heeds recommendations for adjustments to youth sport activities. Multisport activities can largely be done individually in participants' own neighborhoods with simple equipment, reducing constraints related to travel and the provision of elaborate facilities, as well as the needs for teammates and highly developed skill sets. Teaching these activities to youth as a sport option also addresses traditional team sport constraints related to reduced opportunities for participation as children age, as well as high attrition rates [15,19,27]. With opportunities for multisport participation on the rise, as well as higher continuation levels than traditional team sports, introducing youth to these activities enables participation into adulthood [24]. Teaching multisport activities to youth enables skills that can be used to pursue related activities for a lifetime, when many are past the age or desire for team sports participation.

Adding multisport to the list of effective activity choices for youth programs considers Basterfield's [19] recommendations that children be able to sample from a diverse array of activities. A unique aspect of multisport activities are their self-paced nature, enabling participants to be more active in determining the structure of their own participation. This aspect considers Witt \& Dangi's [17] recommendation to allow children more autonomy in pursuing their own motivations in sport, rather than being subject to pre-established metrics of success governed by adults.

\section{Conclusions}

While multisport activities appear to be effective for physical change among youth, further examining these changes specifically among minority or economically disadvantaged youth is important in establishing multisport as a way to address health disparities present in team sport participation for these populations. While the current study established positive changes as resulting from multisport participation in a largely minority sample, future research may further examine differences in ethnic groups regarding perceptions or attitudes of such activities among minority populations. In utilizing the benefits of multisport activities related to physical health, it is critical that participants from various ethnic groups have awareness and exposure to such activities, as well as positive perceptions and associations with them.

Additionally, while attrition rates for youth team sports are well-established, there is limited data regarding longitudinal participation trends of multisport activities from youth to adulthood. It may be beneficial to follow youth multisport participants to determine long-term participation patterns. Further, while there is abundant data describing reasons for dissatisfaction among team sport participation $[17,19,20,28]$, there is limited data examining levels of dissatisfaction that may be evident within multisport participation. Further research may examine various reasons for discontinuation of multisport activities.

While the current study has presented multisport activities as an alternative to structured youth sports in impacting physical fitness markers, it is also important to consider constraints that might be related to multisport. Additional research might assess the availability of safe training areas in communities, and access to quality equipment such as safe swimming areas and bicycles. Determining the availability or providing safe areas within communities may be an important and fundamental determinant of program success.

\section{Limitations}

This study's primary limitation is that participants were part of a structured and controlled 7-week camp, where they were required to participate in swim, bike, and run activities. This study did not take into account participants' 
motivation to engage in such activities on their own. Their self-determined motivation may have influenced their desired level of participation in swim, bike, and run activities, thus leading to higher or lower outcome measures. The work of Ryan and Deci [29] supports this claim, as their research showed that youth who demonstrated higher self-determined motivation toward a given activity were more likely to participate at a higher level of performance for that given activity and improve their overall well-being.

The majority of the participants in the study were also minority youth, and although participation in the swim, bike, and run activities demonstrated significant change for specific outcome measures, it is possible these results would not be generalizable or replicable for a more diverse sample of multisport participants. There has been steady decline in youth sport participation since 2008 [30], and more importantly, things like gender [31], youth with disabilities [32], and family income [9] seem to be significant predictors of youth sport participation. It is possible that these variables limited involvement from these specific groups which may have influenced the overall results of the study.

Results were identified in a pre-post design and not in a longitudinal study, therefore long term impact of participation in the multisport activities is not known. Longitudinal studies typically use continuous or repeated measure in order to follow a group of individuals over a specific time period [33]. For example, a longitudinal study would have followed these participants over a prolonged period of time, with data being collected on a number of identified outcomes in order to determine the relationship between participation in multisport activities and health/fitness benefits.

A paired sample t-test was performed, and although there were significant differences in pre-camp and postcamp scores for body weight, muscular strength, core strength, and resting heart rate, the paired samples t-test does not allow us to determine if participation in the multisport activities caused the change in the fitness markers [34]. Factors such as maturation bias [35], confounding factors [36], and the lack of a control group limits the study findings.

\section{Acknowledgements}

We would like to acknowledge Liz Dobbins and Bernard Lyles for their tireless effort in helping with this study.

\section{Statement of Competing Interests}

The authors have no competing interests.

\section{References}

[1] Ogden, C. \& Carroll, M. (2010). Prevalence of obesity among children and adolescents: United States, trends 1963-1965 through 2007-2008.

[2] Sallis, J. F., McKenzie, T. L., Alacaraz, J. E., Kolody, B., Faucette, N., \& Hovell, M. F. (1997). The effects of a 2-year physical education program (SPARK) on physical activity and fitness in elementary school students. Sports, plays and active recreation for kids. American Journal of Public Health, 87(8), 1328-1334.

[3] Gately, P.J., Cooke, C.B., Barth, J.H., Bewick, B.M., Radley, D., \& Hill, A.J. (2005). Children's residential weight loss programs can work: A prospective cohort study of short-term outcomes for overweight and obese children. Pediatrics, 116(1), 73-77.

[4] Klijn, P.H.C., van der Baan-Slootweg, O.H., \& van Stel, H.F. (2007). Aerobic exercise in adolescents with obesity: preliminary evaluation of a modular training program and the modified shuttle test. BMC Pediatrics, 7(19).

[5] Nemet, D., Barkan, S., Epstein, Y., Friedland, O., Kowen, G., \& Eliakim, A., 2005. Short- and long-term beneficial effects of a combined dietary-behavioral-physical activity intervention for the treatment of childhood obesity. Pediatrics, 115(4), 443-449.

[6] Donnelly, J.E., Greene, J.L., Gibson, C.A., Smith, B.K., Washburn, R.A. Sullivan, D.K., DuBose, K., Mayo, M.S., Schmelzle, D.H., Ryan, J.J., Jacobsen, D.J., \& Willilams, S.L. (2009). Physical Activity Across the Curriculum (PAAC): A randomized controlled trial to promote physical activity and diminish overweight and obesity in elementary school children. Preventive Medicine, 49(4), 336-341.

[7] Weintraub, D., Tirumalai, E.C., Haydel, K.Fl, Fujimoto, M., Fulton, J.E., \& Robinson, T.N. (2008). Team sports for overweight children: The Stanford Sports to Prevent Obesity Randomized Trial (SPORT). Archives of Pediatric and Adolescent Medicine, 62(3), 232-237.

[8] Cliff D.P., Okely, A.D., Morgan, P.J., Jones, R.A., \& Steele, J.R. (2010). The impact of child and adolescent obesity treatment interventions on physical activity: A systematic review. Obesity Management, 11(7), 516-530.

[9] Aspen Institute (2017). The state of play 2017: Trends and developments

[10] Fraser-Thomas, J.L., Côté, J., \& Deakin, J. (2005). Youth sport programs: An avenue to foster positive youth development. Physical Education and Sport Pedagogy, 10(1), 19-40.

[11] Lee, J.E., Pope, Z., \& Gao, Z. (2018). The role of youth sports in promoting children's physical activity and preventing pediatric obesity: A systematic review. Behavioral Medicine, 44(1), 62-76.

[12] Smith, L. (2003). Peer relationships in physical activity contexts: a road less traveled in youth sport and exercise psychology research. Psychology of Sport and Exercise, 4(1), 25-39.

[13] Pate, R.R., Trost, S.G., Levin, S., \& Dowda, M. (2000). Sports participation and health-related behaviors among U.S. youth. Archives of pediatric and adolescent medicine, 154(9), 904-911.

[14] Taliaferro, L.A., Rienzo, B.A., \& Donovan, K.A. (2010). Relationships between youth sport participation and selected health risk behaviors from 1999 to 2007. Journal of School Health 80(8), 399-411.

[15] Belanger, M., Townsend, N., \& Foster, C. (2011). Age-related differences in physical activity profiles of English adults. Preventive Medicine, 52, 247-249.

[16] Bowers, M.T. \& Ozyurtcu, T., (2018). Reducing bias to shift demand: A model for reforming youth sports in America. Sport \& Entertainment Review, 4, 33-40.

[17] Witt, P.A., \& Dangi, T. (2018). Why children/youth drop out of sports. Journal of Park and Recreation Administration, 36, 191-199.

[18] O’Reilly, N., Berger, I.E., Hernandez, T., Parent, M.M., \& Seguin, B. (2015). Urban sportscapes: An environmental deterministic perspective on the management of youth sport participation. Sport Management Review, 18(2), 291-307.

[19] Basterfield, L., Gardener, L., Reilly, J.K., Pearce, M.S., Parkinson, K.N., Adamson, A.J., Reilly, J.J., \& Vella, S.A. (2016). Can’t play, won't play: Longitudinal changes in perceived barriers to participation in sports clubs across the child-adolescent transition. BMJ Open Sport and Exercise Medicine, 2(1).

[20] Harris, S., Nichols, G., \& Taylor, M. (2017). Bowling even more alone: Trends towards individual participation in sport. European Sport Managmeent Quarterly, 17(3), 290-311.

[21] Sports and Fitness Industry Association (2018). Sports, Fitness, and Leisure Activities Topline Participation Report.

[22] Oja, P., Titze, S., Kokko, S., Kujala, U.M., Heinonen, A., Kelly, P., Koski, P., Foster, C. (2015). Health benefits of different sports disciplines for adults: Systematic review of observational and intervention studies with meta-analysis. British Journal of Sports Medicine, 49, 434-440. 
[23] Pons-Villanueva, J., Segui-Gomez, M., \& Martinez-Gonzalez, M.A. (2010). Risk of injury according to participation in specific physical activities: a 6-year follow-up of 14356 participants of the SUN cohort. International Journal of Epidemiology, 39(2), 580-587.

[24] Brooke, H.L., Corder, K., Griffin, S.J., van Sluijs, E.M. (2014). Physical activity maintenance in the transition to adolescence: A longitudinal study of the roles of sport and lifestyle activities in British youth. PLoS One, 9(2).

[25] Tammelin, T. Näyhä, S., Hills, A.P., \& Jarvelin, M. (2003) Adolescent participation in sports and physical activity. American Journal of Preventive Medicine, 24(1), 22-28.

[26] Plowman, S.A. (2013). Muscular Strength, Endurance, and Flexibility Assessments. In S. A. Plowman \& M.D. Meredith (Eds.), Fitnessgram/Activitygram Reference Guide (4th Edition) (pp. Internet Resource). Dallas, TX: The Cooper Institute, 8-1 - 8-55.

[27] Physical Activity Council (2018). 2018. Physical activity council participation report.

[28] Butcher, J., Linder, K.J., \& Johns, D.P., (2002). Withdrawal from competitive youth sport: A retrospective ten-year study. Journal of Sport Behavior, 25(2), 145-163.

[29] Ryan, R., \& Deci, E. (2000). Self-determination theory and the facilitation of intrinsic motivation, social development, and well-being. American Psychologist, 55, 68-78.

[30] Aspen Institute. (2016). State of Play 2016: Trends and Developments. Retrieved from http://www.aspenprojectplay.org/sites/default/files/StateofPlay_20 16_FINAL.pdf.

[31] Phillips, J. A., \& Young, D. R. (2009). Past-year sports participation, current physical activity, and fitness in urban adolescent girls. Journal of Physical Activity and Health, 6(1), 105-111.

[32] Fitzgerald, H. (2009). Disability and youth sport. London, UK: Routledge.

[33] Van Belle G., Fisher L., \& Heagerty P. J. (2004). Biostatistics: A Methodology for the Health Sciences. Longitudinal Data Analysis. New York, NY: John Wiley and Sons.

[34] Pallant, J. (2013). SPSS Survival Manual: A Step-by-step Guide to Data Analysis using SPSS version 15 ( $3^{\text {rd }}$ ed.). New York, NY: McGraw-Hill.

[35] Lewis-Beck, M., Bryman, A., \& Futing Liao, T. (2004). The SAGE Encyclopedia of Social Science Research Methods. Retrieved from http://sk.sagepub.com/reference/socialscience.

[36] Liu, J., Brodley, C. E., Healy, B. C., \& Chitnis, T. (2015). Removing confounding factors via constraint-based clustering: An application to finding homogenous groups of multiple sclerosis patients. Artificial Intelligence in Medicine, 65(2), 79-88.

C The Author(s) 2019. This article is an open access article distributed under the terms and conditions of the Creative Commons Attribution (CC BY) license (http://creativecommons.org/licenses/by/4.0/). 